\title{
Regional health network in the Amazonian context: the case in Manaus, Entorno and Alto Rio Negro
}

\author{
Amandia Braga Lima Sousa 1 \\ Luiza Garnelo 2 \\ Paulo Henrique dos Santos Mota 3 \\ Aylene Bousquat 4

\begin{abstract}
1,2 Laboratório SAGESC. Instituto Leônidas \& Maria Deane. Fundação Oswaldo Cruz Amazônia. Manaus, AM, Brasil.
3,4 Departamento de Política, Gestão e Saúde. Faculdade de Saúde Pública. Universidade de São Paulo. Av. Dr. Arnaldo, 745. São Paulo, SP, Brasil. CEP: 01.246-904.

Email: paulohsmota@gmail.com
\end{abstract}

\begin{abstract}
Objectives: to analyze the dimensions of policy, structure and organization in the construction of Redes de Atenção à Saúde (RAS) (healthcare networks) in the health region of Manaus, Entorno and Alto Rio Negro, focusing on Atenção Primária à Saúde (APS) (primary healthcare) and Rede de Urgência e Emergência (RUE) (urgency and emergency network).

Methods: a case study with multidimensional analysis using quantitative and qualitative approach carried out in the first semester of 2016.

Results: 37 interviewed key informants, such as managers (States, Cities and Regionals), providers and civil society. The reality was marked by the difficulties in the implementation of RAS's with centralized decision-making powers of State level. Perception of insufficient human resources of limited installed capacity, particularly in the APS, with insufficient priority given to this level of care. Concentration of services in Manaus, priority for urgency and emergency actions expressed in the greatest investment in human resources and materials allocated at this level of care, lack of proposals for promoting equity.

Conclusions: the Region was unable to implement RAS to respond to the health demands in the region. The necessity to overcome the dependency relation with the cities and the State and to strengthen its protagonism and fulfillits roles in management network, instituting a plan capable of strengthening APS to be committed in reducing iniquities and with adequate responses in health needs.
\end{abstract}

Key words Community networks, Regionalization, Amazonian Region 


\section{Introduction}

One of the main features in the Brazilian territory is the existence of significant regional inequalities, which expresses socially and economically. Santos and Silveira ${ }^{1}$ analyzed the historical and geographic process in the construction of the Brazilian territory, which identifies as the four Brazils: the Concentrated Region is formed by Southeast and South; the Northeast of Brazil; the Midwest and the Amazon, each of these with its own characteristics. Concerning the Amazon territory, which is the focus of this article, the main traits are the demographic rarefaction and the low techniquedensities. ${ }^{1}$ The demographic rarefaction is not the synonymous of absence in the large urban nucleus, but the concentration of significant portion of the population in a few population nucleus associated to the great population dispersion of the Countryside in the vast territory. These most important cities are places that integrate nationally and internationally in the territory of the Country.

To ensure the universality and comprehensiveness of healthcare in the unequal and continental scenario of these four Brazils has been a constant challenge in the Sistema Único de Saúde (SUS) (Public Health System) implementation. Without a doubt, in the Amazonian Brazil, this challenge is even greater; it is worth noting that the guarantee in having access to health services in remote areas and the difficult access are also a problem in various health systems. ${ }^{2}$ Even so, it was only in 2010 that the Federal Government enacted the Decree number 4,279/10,3 which defined the Healthcare Networks (RAS) as a strategy to overcome the healthcare fragmentation and to ensure the healthcare user with a set of actions and integrated services with quality, effectiveness and efficiency. The Decree number $7,508 / 11,4$ also deals regarding to SUS organization, the health planning, the healthcare and the interfederative articulation setting the Health Region as a central axis to accomplish these provisions.

In 2011, the Decree number1.600/11was edited, instituting the Rede de Urgência e Emergência (RUE) (Urgency and Emergency Network), aiming for the strategic expansion to have access and reception of acute cases demanded to health services through risk classification and adequate intervention for different illnesses in articulation with Atenção Primária à Saúde (APS) (Primary Healthcare) through a regionalized healthcare network. ${ }^{5}$

For the proper organization of regional healthcare networks is essential for the policy alignment organization on health actions among different agents involved in its construction along with the APS that occupy a strategic position of the population's healthcarecoordination. 6

The Amazonian territory is the focus of this article and is marked by the demographic rarefaction distribution in rural areas with low technological density and concentration of health resources in a few urban nucleuses which are highly populated. These cities are part of the Amazon in the country, but their relation with the adjacent cities is the periphery center type, in which occupies a central role, ${ }^{1}$ establishing a web of relations that equally molds the interactions techniques and policies instituted in the healthcare system. The considerable concentration of services of medium and high complexity in the two large capitals, Manaus and Belém, exacerbates the fragmentation and the insufficient provision of healthcare in other cities. 7

The analysis available on the regionalization process in the Country 8 shows that the Amazon was the last State to join the Pacto pela Saude (Health Pact) and that persists with an incipient institutionality and indefinite governance in respect to health regionalization. Lima et al. 6 analyzed the implementation of the regionalization policy in the States of the Country, demonstrating that the Amazon presents an incipient institutionality and indefinite governance with impacts and embryonic institutional innovations in respect to health regionalization. ${ }^{8}$

The slow pace and the little importance given to the regionalization process in the policy sphere are opposed to the necessities in health of the State, which perpetuates an unequal reality. It is, in this sense, the concentration of health resources in a single city, its capital, where they are $53.3 \%$ of hospitalization beds, $100 \%$ of the hospital beds are for Intensive Care Unit (ICU), $94.7 \%$ are for the urgency and emergency of the State, $76.1 \%$ are of the medical professionals and $100 \%$ are of the tomography and magnetic resonance imaging equipment, ${ }^{9}$ which obliges users to go to Manaus even to do simple tests and have consultations with specialists which do not exist in smaller towns.

Among the Amazonians'health regions, Manaus, Entorno and Alto Rio Negro regions which houses its capital, stands out to unite more than $60 \%$ of the population. Also in this region it is possible to emphasis clearly the contrast between the attempt to construct health strategies that are capable of a greater distribution of services and the concentration of these in the largest city in the Amazon, Manaus, and the reality of the cities reduce in rarefaction contrast with restricted availability of health professionals, social indicators and unfavorable sanitaries, 
high dependence on Federal transfers and limited resource capacity for health action costing, this is the reality of small towns in the Amazon. 6

Considering this context, the present article analyzes the dimensions of policy, structure and organization establishments and health actions in selected regional, deepening the analysis on two key elements in the RAS: the APS, due to its role as the entry and the coordination system and RUE for its structuring role on the construction of the care networks 9 in health region in Manaus, Entorno and Alto Rio Negro.

\section{Methods}

The Case study was carried out in the research scope on the Politica, Planejamento e Gestão das Regiões e Redes de Atenção à Saúde no Brasil na região (Policy, Planning and Management of the regions and Healthcare networks in the region of Brazil) "Manaus, Entorno and Alto Rio Negro - AM". The choice of this health region was set off from the typology of 431 Brazilian health regions that were based on the socioeconomic situation and the complexity and the offering of health services. 10 Among the 12 Cities that make up the region; three were selected to take part of the research field. The criteria used were policy, geographical, population and the number of health services. Manaus (the Capital of the State and the pole City of the health region); São Gabriel da Cachoeira (A far away City from the pole, population and the number of intermediate health services for the region); and Careiro da Várzea (near Manaus but no territory connection with the capital with a small number of health establishments and inhabitants.

The methodological approach of this study relied on the use of instruments of analysis on public policy to understand the regionalization process. ${ }^{11}$ Due to the complexity of this, we chose to perform dimensional analysis by adding three dimensions, policy, structure, and organization, which explains by itself, if not, all, at least part of the operational networks in healthcare in the studied region.

In the Policy dimension, based on the concept of governance, which redefines and expands the different forms to relate among the State and the society or even among different governments, agents from the private sector and society members 12 were investigated by the policy processes seeking to identify the performance spaces, negotiation, conflict and the processes and flowing decision-making in policy conduct in the region. The Structure dimension was analyzed from the conditioned regional dynamics, the availability and sufficiency of human resources beyond the capacity of installed services. On the last dimension, Organization, it aimed to identify the conformation criteria of RAS, its planning, management and systemic integration. Table 1 summarizes the analytical matrix used to approach the data produced in this present study.

Structured and semi-structured interviews were conducted using quantitative and qualitative approach with 37 agents, of these, 24 in Manaus, seven in Careiro da Várzea and six in São Gabriel da Cachoeira. In relation to the number of managers, three were State, one regional manager and 14 cities. There were seven providers at State level and eight at city level and three representatives of society through the city health councils.

The results were entered in the database through the PHP Line Survey software - Open Source. For the quantitative analysis of the results, a SPSS Statistics software, version 22.0 was used. The questionnaire was composed by several question formats (yes/no; the Likert scale semi-open;) and the responses were analyzed in percentages, in the case of the yes/no questions. The questions answered in the Likert Scale were transformed into numbers (the averages ranging from always/very important/very high $=5$ up to no importance/never/very low $=1$ ), and calculated the average per item responded.

The semi-structured interviews followed a script composed of questions which also proposed to investigate closely the dimensions discussed in this study and from the historical institutionalism approach 13,14,15 appreciating the historical-structural factors, institutional policy and relational as determinants of health governance were analyzed.

This study was approved by the Ethics Committee at the Faculdade de Medicina da Universidade de São Paulo, under the process number $071 / 15$, CAAE number: 42787815.9.1001.0065 according to the National Health Council Norms 466/12.

\section{Results}

The Secretaria Estadual de Saúde (SES) (Health State Department) was considered the main institution organizer of RAS by $70.8 \%$ of the respondents. This is also the institution, the most influential for decision-making in the region, followed by far by the Secretarias Municipais de Saúde (SMS) (City Secretaries of Health) and COSEMS (Conselho Secretários Municipais de Saude) (City Council Health Secretaries). The relevance of the SES is even clearer in the 
Table 1

Analytical matrix of the study. São Paulo, 2017.

\begin{tabular}{lcc}
\hline Dimension & Determinants of Regional Dynamics & Items of Analysis \\
\hline Policy & Governance & Decision-making process \\
& & Decision-making \\
& Policy Protagonism
\end{tabular}

Structure

Infrastructure

Human Resources

Organization

Conformation of health care networks

Systemic Integration

Planning
Adequacy of installed capacity

Professional sufficiency

Problem Solving

Promptness

Diagnosis of necessities

Line management

Mechanisms for integrating APS-RUE

Services and health actions

Financing

APS = Primary Healthcare; RUE= Urgency and Emergency Network.

managers'statements:

"Here exists a very parental characteristic, it is the culture of the city administration... we arrive in one of these cities, which mayor will buy an ambulance? No one, he will request an ambulance in the State government".

On the other hand, this emphasizes that the low relevance of organs such as the Ministério Público (Public Ministry) (mean score - 2.5) and the judiciary organs (mean score 2.0), denotes a lack of integration and interest of the entity with the health theme, which, in fact, has been restricted to the care of the executive organs.

Another central theme in the policy dimension is the role of the Comissão Intergestores Regional (CIR) (Regional Inter-managers Comission), this was considered as a area of an average importance for decision-making in the health region, according to the interviewees. Its character is deliberative and the format to discuss regionalization occurs through working groups, committees and formal meetings. Regarding to the role of the CIR, the managers' perception indicates several weaknesses, especially in the formation of care networks in the financing negotiations and the establishment of relations between public and private entities. The performance of the CIR was evaluated as indifferent when it was related to the integration and negotiation processes in favor of improvements in the health framework articulated among cities.

The political party disputes among leaders (especially those that passes through the relations of mayors among themselves, and sometimes, the secretaries, and are seen as future rivals in the dispute for the next election) that were also cited as an essential element in the managers'reports, which deepens the controversial around the costing of actions and the making of agreement proposals on the network.

The Structure dimension as it was investigated, the data about the relative participation of each government sphere on financing, the interviewees indicated that the State sphere presents a mean score 
of 2.5 for RAS and 2.2 for APS (between low and medium), while showing a 3.4 score for RUE (between medium and high).

The installed capacity of RAS was considered inadequate for health needs by $63.6 \%$ of the interviewees, the parameters on high scores of adequacy were for specialized consultations, number of hospital beds in general and the offering of serviços de apoio diagnóstico e terapêutico (SADT) (support services for diagnosis and therapeutic treatment) for the average complexity (33.3\%) (Figure 1). The sanitary transportation was considered sufficient for only $58.3 \%$ of the interviewees. Different profile of responses was observed in terms of Telehealth services, considering that $83.3 \%$ of the interviewees thought it was sufficient. The standard of sufficiency in relation to RUE is also fragile with $56.2 \%$ of the interviewees considering the pre-hospital care as sufficient and
$47.0 \%$ of SADT offering and portable pre-hospital care. The APS presented an index of sufficiency even lower than those previously presented with $35.3 \%$

In Figure 2 demonstrates the interviewees' perception on the sufficiency of professionals in RAS, RUE and APS. It is possible to verify that for the interviewees, there is an insufficiency of available professionals in all these situations. However, the insufficiency is higher in the professionals that form the APS teams, mainly those who are referred as physicians and other professionals with higher schooling level.

For the integrated organization of RAS services in the region, the first step pointed out by the interviewees would be better performance and the expansion of the Serviço de Atendimento Móvel de Urgência (SAMU) (Mobile Urgency Care Service) and consequently, RUE. This logical structure and

Figure 1

Adequacy to service necessities of the installed capacity of RAS (\%). Manaus, Entorno and Alto Rio Negro, 2016.

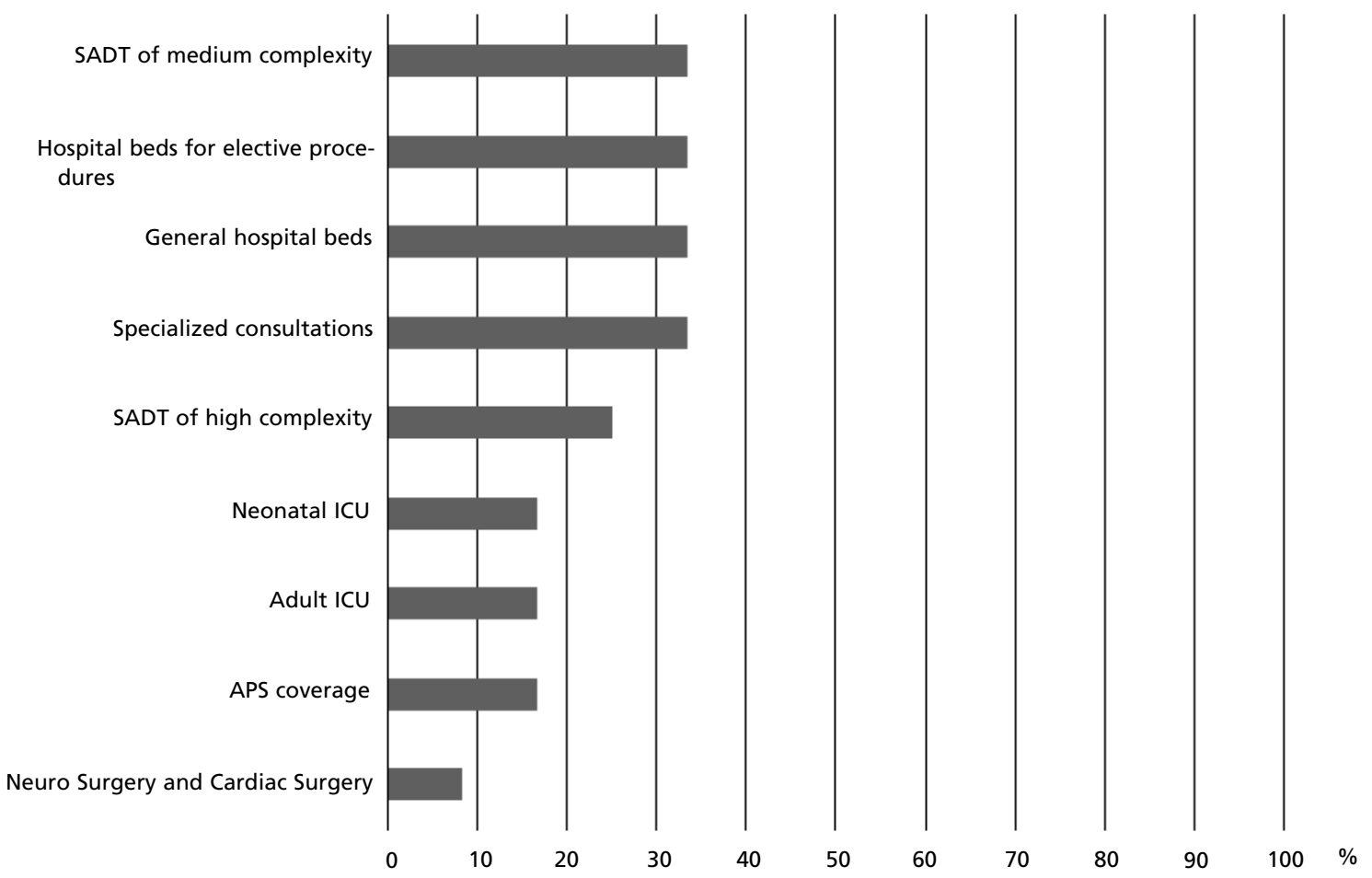

RAS = Healthcare Networks; SADT= services for diagnosis and therapeutic support; APS = Primary Healthcare; ICU= Intensive Care Unit. 
Figure 2

Sufficiency of human resources (\%) in RAS, RUE and APS. Manaus, Entorno and Alto Rio Negro, 2016.

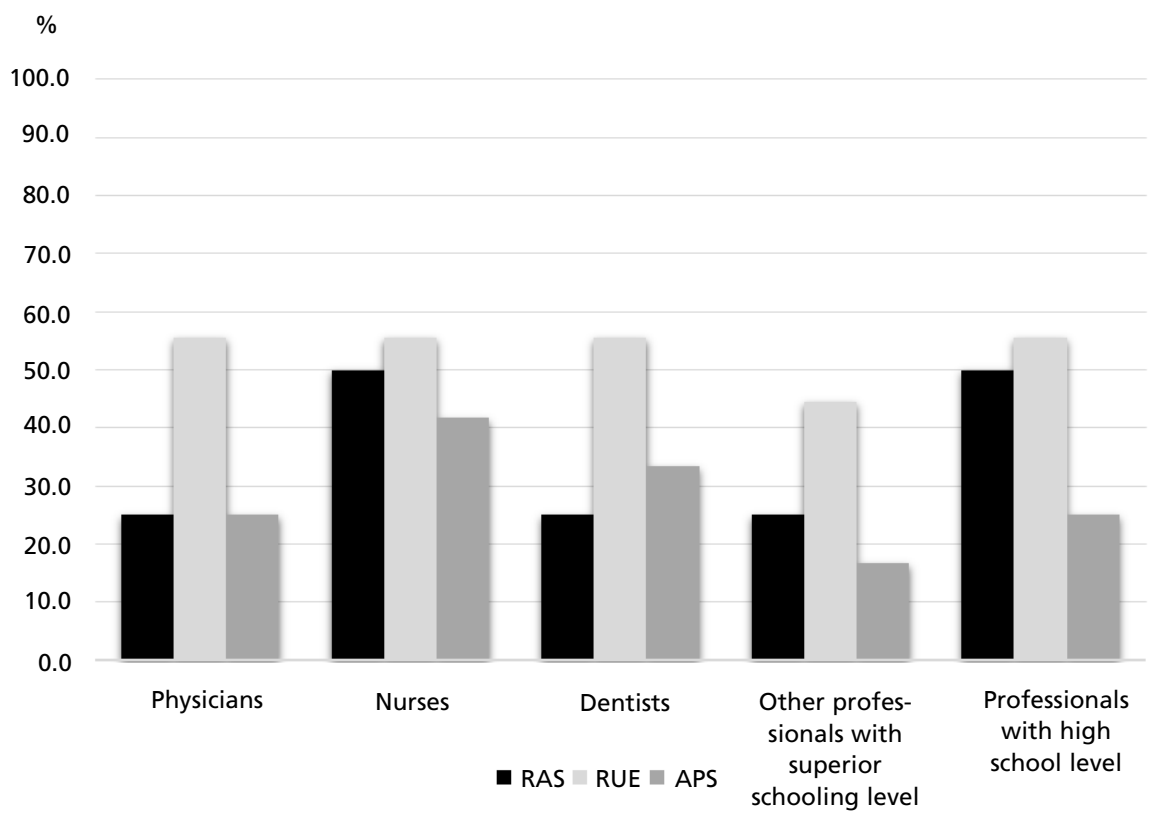

RAS = Healthcare networks; RUE= Urgency and Emergency Network; APS = Primary Healthcare.

investment for RAS through the urgency and emergency actions is connected to specific historical features of the region, such as the construction of hospitals in each of the 62 towns in the State, and its construction and maintenance costing would be funded by the State Health Department, registering low use of hospital beds in certain locations, as presented in this excerpt from the manager's speech:

"For example, in the former governor's town at the time with 42 thousand inhabitants, a hospital with 100 beds was implanted with semi-intensive project. I dedicated myself to verify the occupancy rate of this hospital and it never increased more than $25 \%$, in other words, a structure waiting for the wind, this resource could be better used".

For the $62.5 \%$ of the interviewees, the criteria for planning RUE were the Regional Plan for adequacy of offering specialized services, diagnostic and therapeutic support, and the regional diagnosis of installed capacity in the health services. When asked about the existence of the monitoring and evaluation processes, $50 \%$ of the interviewees stated there were no such actions, the other interviewees affirm that these processes exist, but they did not know how to specify exactly what they were. In addition, the interviewees indicate that RUE contributed little to the integration of the regional services network and to enhance the offering/coverage of APS.

On the other hand, in the interviewees' speech, there is a silence concerning APS, as if it did not take part of the regionalization process, appearing only to cite the relation among the low resolution at this level of care and the high rates of hospitalization. Thus, the promptness in service and problem solving, $33.4 \%$ of the interviewees evaluated that the management at the APS has guaranteed the aspects cited. Now, when questioned about the management at RUE, $44.4 \%$ of the interviewees evaluated that this guarantee is prompt for service and $55.6 \%$ in solving the user's health problem.

For the planning the organization of APS, the interviewees cited the diagnosis of healthcare necessities; a regional plan to adequate the offering of specialized services; a regional plan for expanding the offering in primary care; and the regional diagnosis installed capacity in the health services, all with percentages below $60 \%$.

The line management at APS, according to the interviewees, incorporates the analysis of risk and vulnerability in receiving the user at APS "sometimes" (mean score - 3.4). However, the action 
program based on risk criteria; protocols on risk stratification in emergency situations; and monitoring situations of greater risk at APS to other care points which "rarely" happens.

Evaluation and monitoring actions are carried out at APS by means of the indicators'performance by $66.7 \%$ of the interviewees. However, the use of the results for service improvement is only performed "sometimes" (mean score - 2.9). Even though, the interviewees were asked what would be the use of the indicators' performance, most of them did not mention, or pointed out only the use of the Programa de Melhoria do Acesso e da Qualidade (PMAQ) (Improve Access and Quality Program).

Both RUE as APS present a low percentage of positive responses on the integration of its operation. The affirmative statement on integration between Atenção Primária à Saúde (Primary Healthcare) and the Rede de Urgência e Emergência (Urgency and Emergency Network) has a mean score of 1.3. Even less are the scores related to the notification for hospitalization at APS and in receiving the hospitalization report by the physician at APS after hospital discharge (mean score - 1.1); these scores indicate that these actions are not performed. The communication among the professionals in different levels of healthcare is also interpreted as inefficient; it was not appointed in sharing responsibilities among APS and Hospital/Specialized caren or the existence of information flows in a timely manner.

\section{Discussion}

The implementation form of health services in the Amazon State, in the course of history, is dependent on external and punctual projects, planned for most part, at a National scope. These services are to be incorporated into the State management, but end up resulting in the concentration of power and influence on health in the State organ. ${ }^{13}$

As verified in the results, the SES was pointed out as an instance of great importance in the regionalization implementation which indicates the permanence of its centrality in this context. As for the centralization versus decentralization discussion in the regionalization scope, Ribeiro et al.14 reenforces the difficulty of the inter-cities and, according to their analysis, they defend that a more centered intervention as a necessity for a greater equity.

Other studies also indicate the centered action in the State as positive action, as being a facilitator within the negotiating instances and an encourager of the decisions made collectively. 15 However, the analysis on the policy dimension in this health region according to the interviewees' responses revealed a State action that is more towards acting in places of the towns than, in fact, contribute for a protagonism and a joint construction and solidary between the Federated entities. This form of the State to act had already been evidenced in a study with five towns in the Amazon State that sought to analyze the basic care and observed the dispute of the execution of actions at this level of care among the Cities and State. 16

The State centrality is adding weaknesses in the collective negotiations of CIR, which brings impacts to the constitution of RAS and in the form of how it consolidates to APS and RUE. The limitations of CIR create an action model of bureaucracy at the detriment of setting up as a collective construction space. ${ }^{17}$ Lima et al., 6 emphasize the existence of an association between regionalization and the policies of each territory, constituting itself as fundamental point between the Cities and the State, in particular, about the ability of these entities in sharing responsibilities.

RUE deployment in the region began with SAMU, the reality is also observed in other contexts. 18 The proposed organization of SAMU in the metropolitan region contemplated two more health regions, moreover, all with resolution in Manaus. According to one of the managers, this design was created to cover $60 \%$ of the population in the State. The justification is to ensure service in most of the State of medium and high complexity in the Capital. However, this indicates a lack of commitment with the distribution of services and with the equity in this health region, as proposed in the regionalization policy. ${ }^{19}$ Instead of thinking this way, the network points out to the current operational maintenance with the health resources concentrated in a single City, while complying the relations between Cities in a binary form and not in the network. ${ }^{17}$

The analysis of the results shows that RUE was not an effective response to integrate services in this health region, with the aggravating factor of being little integrated into APS. Whereas, the latter is as an important component of RUE and before the results are presented, it is evident the operation of this network from a centered disease model with strong emphasis on the spontaneous demand and deepening chronic conditions similar to what occurs in other territories. 20 However, considering this study is dealing with the health region in a discontinuous territory of long distances and high cost locomotion, this reality has become even more contradictory. It is 
getting worse that the fact of the interviewees' perceptions, the financing for APS on behalf of the State is between low and medium, which represents a contradiction of the consensus that the investment in APS requires improvement of health conditions and a decrease in the number of hospitalizations, obtaining as a result of an optimization in financial resources to be applied in health. ${ }^{21}$

In fulfilling its role, APS presented weaknesses, including when it was evaluated regarding to the ability to ensure greater promptness and resolution in health matters, having RUE obtain a better evaluation regarding this aspect. This low potentiality of APS to ensure satisfactory answers goes against what is proposed in the policy of RUE deployment which, considering APS as part of this network, it advocates for the beginning of its organization for this level of care with an emphasis on the responsibilities, among them, the operational of the networks, monitoring flows and the coordination in care. 22

Also in relation to APS, there are negative points about this level of care in several areas, including in regard to its interaction with RUE. Thus, even though RUE has presented a better responsiveness to the health issues, APS presents limitations in its relation with this network service which denounces serious compromises in the composition of the studied RAS, since this implies the fulfillment of the role in the network and overcoming the fragmentation of the territory. $22 \mathrm{~A}$ bad evaluation on APS had already been observed in a study that evaluated the data program of the Programa de Melhoria do Acesso e da Qualidade (PMAQ) (Access and Quality Improvement Program)that qualified APS services in the Amazon as the worst quality from the rest of the Amazon region and in Brazil.23

Within larger scope, these disappointing results for APS imply the operational of RAS, since it is far from acting as a coordinator of this network and as an effective entrance to the network. 24

On the other hand, the responses revealed the absence of an effective participation of the State in planning, organization and implementation of APS in the health region. According to these data, the State has not fulfilled its role as a promoter of policies 25 in terms of APS.

The difficulty of ensuring human resources in remote areas is a common problem in other countries, such as Australia, having been recognized as the "tyranny of distance".26 In addition to the needs presented at all levels of care, it emphasizes on the interviewees' understanding that APS counts on the most insufficiency of professionals, even when comparing to RUE and RAS. The absence of the physicians at the APS is recognized as an important factor in the increase of hospitalizations due to sensitive causes at APS. ${ }^{27}$ On the other hand, considering the specific issues in that region, there is the need of distributing professionals at APS, with the concern that they occupy spaces that, in fact, will result in better equity in health.

On the interviewees' evaluation, RUE has not managed to fulfill its role as a fragmentation which still remains in function of the services in this health region. A central point for this discussion is the need to construct a collective planning that seeks greater equity, as being discussed, if the operational format networks, prepared by the federal legislation, would be the best way or if there would be other ways of working, considering the local specificities. However, as regard to the planning construction, the interviewees identified a low utilization on the existing documents to base their choices of action. This reality is becoming worse by the result on the analysis of the management processes on primary care in the Amazon according to Vieira et al.16 This study 16 recognized the difficulties of the cities to identify priorities, lack of financial capacity and support base for policy to put into practice what was already planned.

An adequate planning to seek better equity in this region, it could, in the terms proposed by Viana et al., 19 point out clear and rigorous criteria for the use of available resources as this being a central point for a good deployment of public policies.

The Structure dimension was analyzed as an important strategy for the Programa Telessaúde (Tele-health Program).28 As the interviewees' opinions, it has been configured as the possibility to integrate services, as it received a good evaluation by being considered as significant strategy, also in the interviewees' speech. The use of technologies, similar to what happens in remote regions in other Countries 29,30 has been established to be useful in conducting medical care and specialized tests by means of an exchange among the professionals.

It is worth noting that the results of this study refer to the perception of the own agents at RAS in the region, and that, despite trying to deal with the complexities of the theme, using and analyzing different instruments in the attempt to capture its peculiarities, unique situations in this region were not the object of this research - despite the recognition of its importance in this context - among them, the indigenous issues and the territories of international border. Another important point to 
emphasize in this study was the methodology applied. When using the method of case studies this opens the possibility of studying a case deeply, emphasizing the context in which the phenomena occurs and promotes the understanding of the processes and results. On the other hand, as a limiting factor, the case study, does not favor its replication and generalization, which was not the objective of this article.

\section{Conclusion}

The operational analysis on RAS in the region, from the perspective of the studied dimensions, emphasizing RUE and APS, indicates that the regional has not yet been able to deploy the

\section{References}

1. Santos M, Silveira ML. O Brasil: território e sociedade no início do século XXI. 8 ed. São Paulo: Record; 2008.

2. Rechel B, Džakula A, Duran A, Fattore G, Edwards N, Grignon $\mathrm{M}$, et al. Hospitals in rural or remote areas: An exploratory review of policies in 8 high-income countries. Health Policy. 2016; 120 (7): 758-69.

3. Brasil. Ministério da Saúde. Portaria GAB/MS no 4.279, de 30 de dezembro de 2010. Estabelece diretrizes para a organização da Rede de Atenção à Saúde no âmbito do Sistema Único de Saúde (SUS). Diário Oficial da União. 2010, dez. 31; Seção 1.p.88

4. Brasil. Ministério da Saúde Decreto $\mathrm{n}^{0} 7.508$, de 28 de junho de 2011. Regulamenta a Lei no 8.080 , de 19 de setembro de 1990, para dispor sobre a organização do Sistema Único de Saúde - SUS, o planejamento da saúde, a assistência à saúde e a articulação interfederativa, e dá outras providências. Diário Oficial da União 2011, jun. 29; Seção 1. p.1-3

5. Brasil. Ministério da Saúde. Portaria GAB/MS no 1.600 , de 7 de julho de 2011. Diário Oficial da União 2011, jul. 8 ; Seção 1, p.1-9

6. Lima LD, Viana ALA, Machado CV, Albuquerque MV, Oliveira RG, Iozzi FL, Scatena JHG, Mello GA, Pereira AMM, Coelho APS. Regionalização e acesso à saúde nos estados brasileiros: condicionantes históricos e políticoinstitucionais. Ciência e Saúde Coletiva, 2012, 17 (11): 2881-2892.

7. Amazonas. Plano Estadual de Saúde 2016 a 2019. http://www.saude.am.gov.br/docs/pes/pes_2016-2019.pdf

8. Região e Redes Caminhos para regionalização no Brasil. $2017 \mathrm{http} / / /$ www.resbr.net.br/indicadores

9. Ibanez, N. Os hospitais e a Rede de Atenção às Urgências e Emergências: desafios. Rev Conselho Nacional Secretários Saúde 2013. 7(3): p. 39-43

10. Viana ALD, Bousquat A, Pereira AP de CM, Uchimura LYT, Albuquerque MV, Mota PH dos S, Demarzo MMP, Ferreira MP. Tipologia das regiões de saúde: condicionantes operation of health networks at capable level of responding the demands in the health region. Healthcare is not being constructed on the basis of a collective discussion which achieves in a plan that represents responses to the demands in the region. The State centrality has shown to be a difficult process, implying problems that need response in order to improve the fragmentation of the services. To emphasize the need to overcome the relation of dependence between Cities and State authorities and to optimize its protagonism and the fulfillment of their roles in management networks by instituting a plan capable of effecting strategies that consolidates APS and establishes program routines committed to reduce inequalities and have adequate responses for health necessities. estruturais para a regionalização no Brasil. Saúde Soc. 2015; 24 (2): 413-22.

11. Donahue JD e Zeckhauser RJ. Public-private collaboration. In Moran, M, Rein, M, Goodin, RE. Ed: The oxford handbook of public policy. Oxford university press; 2006. p. 496-527

12. Albuquerque MV, Scatena JHG. Quem governa e como se governam as regiões e redes de atenção à saúde no Brasil? Contribuições para o estudo da governança regional na saúde. Novos Caminhos, N.8. Pesquisa Política, Planejamento e Gestão das Regiões e Redes de Atenção à Saúde no Brasil (Região e Redes). 2016.

13. Schweickardt JC, Kadri MR, Lima RTS, Ferla AA. História e Política Pública de Saúde na Amazônia como campo de pesquisas. In: História e política pública de saúde na Amazônia. (Orgs) Schweickardt JC, Ferla AA, Lima RTS, Kadri MR. Porto Alegre: Editora Rede Unida, 2017.

14. Ribeiro PT, Tanaka OY, Denis JL. Regional Governance in Brazil's Unified Health System: a conceptual essay. Ciênc Saúde Coletiva. 2017; 22 (4): 1075-84.

15. Machado JA. Pacto de gestão na saúde: até onde esperar uma "regionalização solidária e cooperativa"? Rev Bras Ciênc Soc. 2009; 24 (71): 105-19.

16. Vieira JMR, Garnelo L, Hortale VA. Análise da Atenção Básica em Cinco Municípios da Amazônia Ocidental, com Ênfase no Programa Saúde da Família. Saúde Soc. São Paulo 2010; 19 (4): 852-65.

17. Garnelo L, Lima Sousa AB, Silva, CO. Regionalização em Saúde no Amazonas: avanços e desafios. Ciênc Saúde Coletiva. 2017. 17 (7): 1903-14.

18. Machado C, Salvador F, O’Dwyer G. Serviço de Atendimento Móvel de Urgência: análise da política brasileira. Rev Saúde Pública. 2011; 45 (3): 519-28.

19. Viana ALA, Ferreira MP, Cutrim MAB, Fusaro ER, Souza MR, Mourão L, Chancharulo AP, Mota PHS. Política de regionalização do SUS em debate: avanços e impasses da implementação das regiões e redes no Brasil. Novos 
Caminhos n. 15. [Nota Técnica na internet] 2017. [acessado em 30 de março de 2017]. Disponível em: http://www.resbr.net.br/wp-

content/uploads/2017/04/Novos_Caminhos_15.pdf

20. Venancio SI, Nascimento PR, Rosa TE, Morais MLS, Martins PN, Voloschko A. Referenciamento regional em saúde: estudo comparado de cinco casos no Estado de São Paulo, Brasil. Ciênc Saúde Coletiva. 2011; 16 (9): 3951-64.

21. Bynum JPW; Ross, JS. A Measure of Care Coordination? J Gen Inter Med. 2013; 28( 3): 336-8.

22. Jorge AO, Coutinho AAP, Fagundes AMS, Pequeno CC Carmo M, Abrahão PTM. Entendendo os desafios para a implementação da rede de atenção às Urgências e Emergências no Brasil: uma análise crítica. Divulg Saúde Debate. 2014. 52: 125-45.

23. Garnelo L, Lucas ACS, Parente RCP, Rocha ESC, Gonçalves MJF. Organização do cuidado às condições crônicas por equipes de Saúde da Família na Amazônia. Saúde Debate. 2014; 38 (Número Especial): 158-72.

24. Mendes EV. A construção social da atenção primária à saúde. Conass; 2015.

25. Junior IFB, Silva ZP. Reforma do Sistema de Saúde e as novas atribuições do gestor estadual. São Paulo Perspec. 2004; 18 (3): 47-56.
26. Schoo A, Lawn S, Carson D. Towards equity and sustainability of rural and remote health services access: supporting social capital and integrated organisational and professional development. BMC Health Serv Res. 2016; 16: 111.

27. Castro ALB, Andrade CLT, Machado CV, Lima LD. Condições socioeconômicas, oferta de médicos e internações por condições sensíveis à atenção primária em grandes municípios do Brasil. Cad Saúde Pública. 2015; 31 (11): 2353-66.

28. Souza CRS, Sachett JAG, Lima LS. A telessaúde no Brasil e no Estado do Amazonas como facilitador de conhecimentos em saúde. In: II Congresso Internacional TIC e Educação. 2012, Nov 30 - Dez 02; Lisboa, Portugal; 2012; 207-215.

29. Caffery LJ, Smith AC. Telehealth services in rural and remote Australia: a systematic review of models of care and factors influencing success and sustainability. Rural Remote Health. 2016; 16 (4): 3808

30. Casey M, Hayes PS, Heaney D, Dowie L, Ólaighin G, Matero M, Hun S, Knarvik U, Alrutz K, Eadie L, Glynn LG. Implementing transnational telemedicine solutions: a connected health project in rural and remote areas of six Northern Periphery countries Series on European collaborative projects. Eur J Gen Pract. 2013; 19 (1): 52-8.

Received on June 1, 2017

Final version presented on September 18, 2017

Approved on October 3, 2017 